\title{
Large-eddy simulation of organized precipitating trade wind cumulus clouds
}

\author{
A. Seifert ${ }^{1}$ and T. Heus ${ }^{2}$ \\ ${ }^{1}$ Hans-Ertel Centre for Weather Research, Deutscher Wetterdienst, Hamburg, Germany \\ ${ }^{2}$ Max Planck Institute for Meteorology, Hamburg, Germany
}

Correspondence to: A. Seifert (axel.seifert@dwd.de)

Received: 12 December 2012 - Published in Atmos. Chem. Phys. Discuss.: 17 January 2013

Revised: 25 April 2013 - Accepted: 12 May 2013 - Published: 10 June 2013

\begin{abstract}
Trade wind cumulus clouds often organize in along-wind cloud streets and across-wind mesoscale arcs. We present a benchmark large-eddy simulation which resolves the individual clouds as well as the mesoscale organization on scales of $\mathcal{O}(10 \mathrm{~km})$. Different methods to quantify organization of cloud fields are applied and discussed. Using perturbed physics large-eddy simulation experiments, the processes leading to the formation of cloud clusters and the mesoscale arcs are revealed. We find that both cold pools as well as the sub-cloud layer moisture field are crucial to understand the organization of precipitating shallow convection. Further sensitivity studies show that microphysical assumptions can have a pronounced impact on the onset of cloud organization.
\end{abstract}

\section{Introduction}

Trade wind cumulus clouds are often distributed randomly in space, but they can also occur as cloud streets, clusters or mesoscale arcs (Malkus and Riehl, 1964; Nair et al., 1998). The formation of lines and streets is fairly well understood and dominated by boundary layer vortices which are caused by both dynamic and thermal instabilities (Etling and Brown, 1993; Atkinson and Zhang, 1996; Müller and Chlond, 1996). But although observed during GATE $^{1}$ and documented by Warner et al. (1979) the mesoscale arcs have received very limited attention as a mode of organization for shallow convection. This only changed recently with the Rain in Cumulus over the Ocean (RICO, Rauber et al., 2007) experiment,

\footnotetext{
${ }^{1}$ Global Atmospheric Research Program (GARP) Atlantic Tropical Experiment (GATE).
}

which documented that local rain rates exceeding $1 \mathrm{mmh}^{-1}$ are not unfrequent in the trades and are often associated with arc-shaped cloud clusters (Rauber et al., 2007; Snodgrass et al., 2009; Minor et al., 2011; Zuidema et al., 2012). Such local rain rates are radar-derived rain rates on the scale of an individual radar pixel, i.e., $1 \mathrm{~km}^{2}$ or below. Corresponding area-averaged rain rates on scales of several tens of kilometers are of order $1 \mathrm{mmd}^{-1}$.

During the last decades many hypotheses have been brought forward to explain why shallow cumulus clouds cluster in groups or clumps. Early on, Malkus (1957) argued for the importance of sea surface temperature (SST) anomalies, something which has recently been brought forward again for tropical rainfall patterns by $\mathrm{Li}$ and Carbone (2012). Another important conceptual idea to explain clustering is pre-conditioning, i.e. moistening of the cloud layer by detrainment (Randall and Huffman, 1980; Khairoutdinov and Randall, 2002; Kuang and Bretherton, 2006). This mechanism, which is sometimes called the mutual protection hypothesis, assumes that clouds modify their local environment in such a way that the conditions are favorable for the subsequent formation of secondary clouds. Observations from GATE and RICO, on the other hand, provide some evidence that the formation of cold pools by precipitation plays a major role in the formation of mesoscale arcs (Warner et al., 1979; Zuidema et al., 2012). 
Similar questions about the feedbacks ${ }^{2}$ which lead to the organization of clouds in bigger clusters have been discussed quite extensively for deep convection, especially for radiative-convective equilibrium simulations. For this cloud regime different mechanisms seem to contribute to the clustering or self-aggregation, e.g. cold pools (Tompkins, 2001; Jeevanjee and Romps, 2013) as well as surface flux and radiative feedbacks (Bretherton et al., 2005; Muller and Held, 2012). The effect of precipitation on the formation of downdrafts and cold pools is, of course, most well established for mesoscale deep convective systems for which details can be found in standard textbooks on cloud dynamics (e.g. Cotton et al., 2011). For deep convective squall lines RKW theory (Rotunno et al., 1988) provides a framework to explain the formation, longevity and propagation of such systems.

In the following we present large-eddy simulations of organized precipitating trade wind cumulus clouds (Sect. 2) and we analyze and quantify their organization (Sect. 3). In Sect. 4 the potential feedbacks leading to organization are disentangled and we discuss the structure of the cloud field and the coupling with the sub-cloud layer (Sect. 4). The sensitivities to grid spacing and cloud microphysical assumptions are discussed in Sect. 5, and the paper ends with conclusions and an outlook for future research (Sect. 6).

\section{Large-eddy simulation}

\subsection{Model and case description}

In this study we apply the University of California, Los Angeles large-eddy simulation (UCLA-LES) model which solves the Ogura-Phillips anelastic equations (Stevens et al., 1999, 2005). The prognostic variables are the three components of the velocity, i.e. $u, v, w$, the total water mixing ratio $r_{\mathrm{t}}$, the liquid water potential temperature $\theta_{1}$ as well as the number and mass mixing ratios of rainwater. The most recent version of UCLA-LES uses a third-order Runge-Kutta time integration instead of second-order Leapfrog (Stevens, 2010). The advection of scalars is discretized by a higherorder upwind scheme with monotonized centered slope limiters while 4th-order centered differences are applied for the velocity components. Subgrid fluxes are modeled using the Smagorinsky-Lilly model. Following Savic-Jovcic and Stevens (2008) the cloud microphysical processes are parameterized in UCLA-LES based on the two-moment warm rain scheme of Seifert and Beheng (2001) with some refinements described in detail in Stevens and Seifert (2008, SS08 hereafter). The SS08 implementation assumes a constant cloud droplet number concentration (which is set to $70 \mathrm{~cm}^{-3}$ if

\footnotetext{
${ }^{2}$ By feedback we mean a mechanism that alters the system in such a way, that the mechanism ultimately alters its own drivers, and therefore itself. More specifically, we mean cloud and precipitation processes that alter the mean state of the atmosphere, and through that modify the clouds and precipitation themselves.
}

not mentioned otherwise), i.e., the two-moment approach is only applied for rain, not for cloud droplets. Condensation is treated by a saturation adjustment which is consistent with the use of the $r_{\mathrm{t}}$ and $\theta_{\mathrm{l}}$ as prognostic variables. The evaporation of raindrops is parameterized using a standard bulk approach with an exponential drop distribution and the assumption that the mean diameter is constant for this process, i.e., the more sophisticated scheme of Seifert (2008) is not applied here.

Our simulation setup follows the GEWEX Cloud System Study (GCSS) RICO model intercomparison case of van Zanten et al. (2011) which is a composite case based on several days during an undisturbed period of the RICO field study. Following SS08 we use the standard setup as described by van Zanten et al. (2011) as well as a slightly moister version which differs only in the initial profile of the water vapor mixing ratio (later on addressed as standard and moist RICO). The moister initial condition leads to a faster development of precipitating shallow convection and higher rain rates of roughly $1 \mathrm{mmd}^{-1}$ compared to the drier case which rains only marginally, i.e, of order $0.1 \mathrm{mmd}^{-1}$. This allows us to study these two different regimes using very similar model configurations.

\subsection{A benchmark simulation}

In SS08 the moist RICO simulations used a horizontal grid spacing of $\Delta x=100 \mathrm{~m}$ and a domain size of $128 \times 128$ grid points, i.e. $12.8 \mathrm{~km} \times 12.8 \mathrm{~km}$ (following the computational setup of the GCSS intercomparison). Such a small domain can support only one significant rain event or cloud cluster of precipitating shallow convection at a time, making the precipitation statistics very intermittent. Such a small domain does also not allow for mesoscale organization. As discussed by Matheou et al. (2011) large-eddy simulations of precipitating shallow convection can, in addition, show a strong sensitivity to grid spacing, which makes it questionable whether $\Delta x=100 \mathrm{~m}$ is sufficient for a quantitative simulation of the precipitation amount and subsequent effects of precipitation on the statistics of the flow field. We have therefore performed a benchmark simulation of the moist RICO case with an isotropic grid spacing of $\Delta x=$ $\Delta y=\Delta z=25 \mathrm{~m}$ on a $2048 \times 2048 \times 160$ grid, i.e. a domain of $50 \mathrm{~km} \times 50 \mathrm{~km} \times 4 \mathrm{~km}$. This simulation is only slightly coarser than high-resolution simulations of Matheou et al. (2011) who used $\Delta x=20 \mathrm{~m}$ but the present domain is considerably (more than 4 times) larger. Their simulations of the standard RICO case already suggested the emergence of cloud organization on such scales (cf. their Fig. 9g), but were still not able to show mesoscale patterns that would resemble observed organized cloud fields. Figure 1 gives an example of the evolution of the cloud field in our benchmark simulation. Shown is the synthetic cloud albedo

$A=\frac{\tau}{6.8+\tau}$, 
where $\tau=0.19 \mathrm{CWP}^{5 / 6} N_{\mathrm{c}}^{1 / 3}$ is an estimate of optical depth (Zhang et al., 2005), $N_{\mathrm{c}}$ the (prescribed) cloud droplet number mixing ratio and CWP the cloud liquid water path. Qualitatively these simulated cloud fields compare very well with satellite images, e.g. Fig. 16c of Snodgrass et al. (2009). A movie of the synthetic cloud albedo which is provided as Supplement ${ }^{3}$ provides additional evidence that the simulation is able to reproduce many typical features of organized trade wind cumulus cloud fields, e.g. the mesoscale arcs oriented perpendicular to the mean wind, small clouds which are organized in along-wind rolls and convective outflowforming stratiform cloud areas.

In the following sections the main features and possible causes of the organization are discussed in more detail.

\section{Diagnostics of cloud organization}

One difficulty in studying organization of cloud fields (or any other objects) is the quantification of organization itself. Although the human eye is very efficient in recognizing spatial structures and patterns it can also easily be fooled to see organization in random fields. It is therefore crucial to objectively quantify the mode and evolution of organization. In the following we will present some standard diagnostics of the simulations together with more sophisticated techniques that measure the degree of organization. In this section we focus on three simulations, the benchmark simulation of the moist RICO case and two simulations of the standard and the moist case on a slightly smaller domain of $1024 \times 1024 \times 160$ grid points, i.e. $25 \mathrm{~km} \times 25 \mathrm{~km} \times 4 \mathrm{~km}$.

\subsection{Time series, profiles and Hovmöller diagrams}

The RICO simulations are a representation of trade wind cumulus clouds as they develop in sub-tropical regions dominated by large-scale subsidence. After a short spin-up of $2 \mathrm{~h}$ simulation time, the cloud cover reaches about $15 \%$ with a corresponding domain-averaged cloud liquid water path of $10 \mathrm{~g} \mathrm{~m}^{-2}$ (see Fig. 2). In the standard setup the cloud layer grows slowly with time, reaching $20 \%$ cloud cover and a domain-averaged liquid water path of $30 \mathrm{~g} \mathrm{~m}^{-2}$ after $40 \mathrm{~h}$. Precipitation in the standard case is marginal in the first $20 \mathrm{~h}$ and increases slowly thereafter. The two simulations of the moist RICO case show a more rapid increase in cloud cover and cloud liquid water path, especially between $10 \mathrm{~h}$ and $16 \mathrm{~h}$ of the simulations. The domain-averaged cloud liquid water path reaches peak values of about $60 \mathrm{~g} \mathrm{~m}^{-2}$ during that time. Precipitation starts much earlier than in the standard RICO case and increases strongly in the first $20 \mathrm{~h}$, reaching values of $50-100 \mathrm{~W} \mathrm{~m}^{-2}$ or $2-3 \mathrm{~mm} \mathrm{~d}^{-1}$. An interesting feature of the simulations of the moist case is the sig-

\footnotetext{
${ }^{3}$ Due to the file size limitations for the Supplement the movies have a reduced time span and reduced video quality. The full movies in high quality are available from the authors.
}
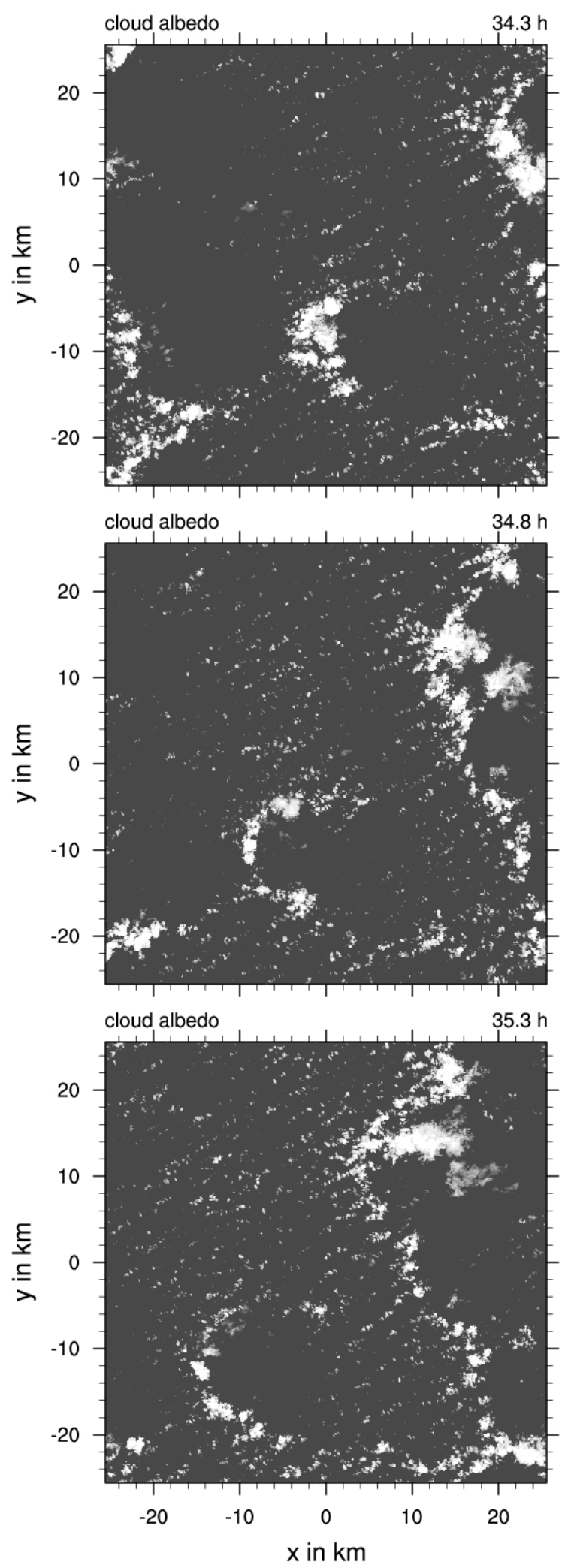

Fig. 1. Synthetic cloud albedo as calculated from simulated cloud liquid water path. Shown are three snapshots with a $30 \mathrm{~min}$ time interval. 
nificant decrease in cloud cover and LWP after $14 \mathrm{~h}$ for the large domain (17 $\mathrm{h}$ on the smaller domain), reaching a quasistationary state after $24 \mathrm{~h}$. An inspection of the evolution of the cloud fields (e.g. the albedo movie) reveals that around $14 \mathrm{~h}$ one big cloud cluster develops in the domain and later this cluster breaks up into smaller lines and arcs. In this sense the first $20 \mathrm{~h}$ of the simulation can be seen as an extended spin-up period which is necessary for the formation of the fully developed mesoscale cloud structures. This behavior is similar on the smaller domain, but this simulation can later support only one single line of clouds. Hence, the time series of LWP and rain rate do still show strong temporal variability for the smaller domain. Both the decrease in cloud cover and LWP, as well as the strong intermittency of the LWP on the smaller domain, suggest that these simulations develop cloud structures which are as large as the domain size. In this sense the time series do give a hint towards mesoscale organization which develops in the moist RICO case. The mean profiles of our simulations as shown in Fig. 3 are, at first glance, very similar to Fig. 1 of SS08. A significant difference is that the mean cloud water mixing ratio in the moist case is actually similar or even lower than in the drier standard case. This makes it somewhat paradoxical that the moist case does in fact rain by a factor of ten more than the standard case. By looking at the mean profiles of cloud fraction, relative humidity, and cloud liquid water, which are all lower in the moist compared to the standard case, one would not expect that the moist case rains so much more readily. The resolution of the apparent paradox lies in the spatial variability, i.e. in the mesoscale organization. Some signal of this can be seen in the variance of total water, which is significantly higher in the moist case.

A simple and efficient approach to study the formation and propagation of organized convective systems are Hovmöller plots (e.g. Carbone et al., 2002). Figure 4 shows Hovmöller plots of the cloud liquid water path (CWP) averaged in northsouth direction. For the standard RICO case the Hovmöller diagram shows the formation and propagation of many individual convective cells. Over the course of simulation time, the size of the convective cells increases slowly. For the moist RICO case on the same domain of $25 \mathrm{~km} \times 25 \mathrm{~km}$, larger structures start to develop after about $13 \mathrm{~h}$, and soon after that the pattern collapses into a single convective line which propagates westwards. For the benchmark simulation on the bigger domain the behavior is similar, with larger structures forming after $12 \mathrm{~h}$, but the Hovmöller plot becomes more chaotic because the organization is more complex and not just a single line of cells. Nevertheless, the overall impression of a big westward-propagating system remains robust.

Given the increase in the rain rate with time and the growth of the cells visible in the Hovmöller diagram it seems likely that the standard RICO case would also transition to the organized regime at some point. Within the $40 \mathrm{~h}$ simulated here this does not happen, but at the end of the simulations the standard case does indeed show more clumpy cloud struc-
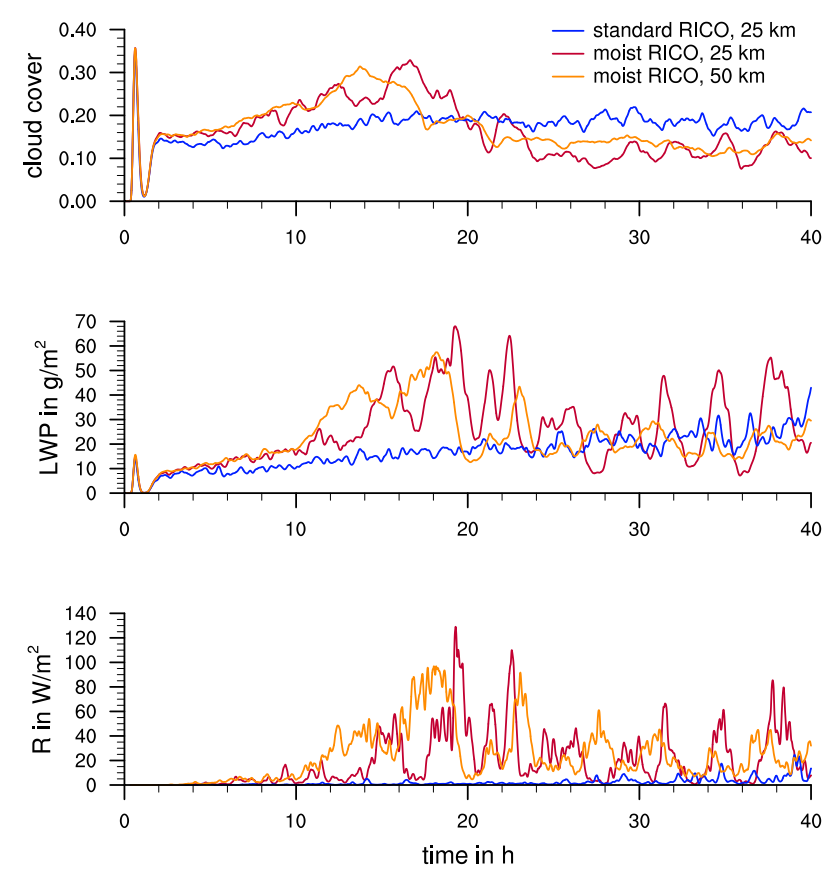

Fig. 2. Time series of domain-averaged cloud cover, liquid water path and precipitation rate for the standard GCSS and the moist RICO case.

tures, which are reminiscent of the early stages of organization in the moist case.

The Hovmöller diagrams are obviously a simple but strikingly powerful tool to detect organization or diagnose the propagation of convection systems, but their main disadvantages are that its character depends on one's choice of averaging direction and that the quantification of organization remains difficult.

\subsection{Fourier analysis}

From a fluid dynamics point of view, the emergence of organized cloud structures is a growth of small scale fluctuations to larger scales. Following de Roode et al. (2004) this can be analyzed by Fourier analysis, i.e. power or variance spectra of various quantities. By using a two-dimensional Fourier transform and averaging in spectral space this avoids any a priori choices about preferred directions. Here we focus for simplicity only on the variance spectrum of the total water, $r_{\mathrm{t}}$, at $1000 \mathrm{~m}$ height (Fig. 5a). Comparing the $r_{\mathrm{t}}$ variance spectra, $S_{r_{\mathrm{t}}}(k)$ with wave number $k$, of the standard and the moist RICO case shows that they are very similar at high wave numbers (small scales) but differ significantly for low wave numbers (large scales). The moist case has much more variance associated with large scale structures that arise from organized convection. As in de Roode et al. (2004) we define a spectral length scale $\Lambda_{r}=1 / k_{r}$ by 

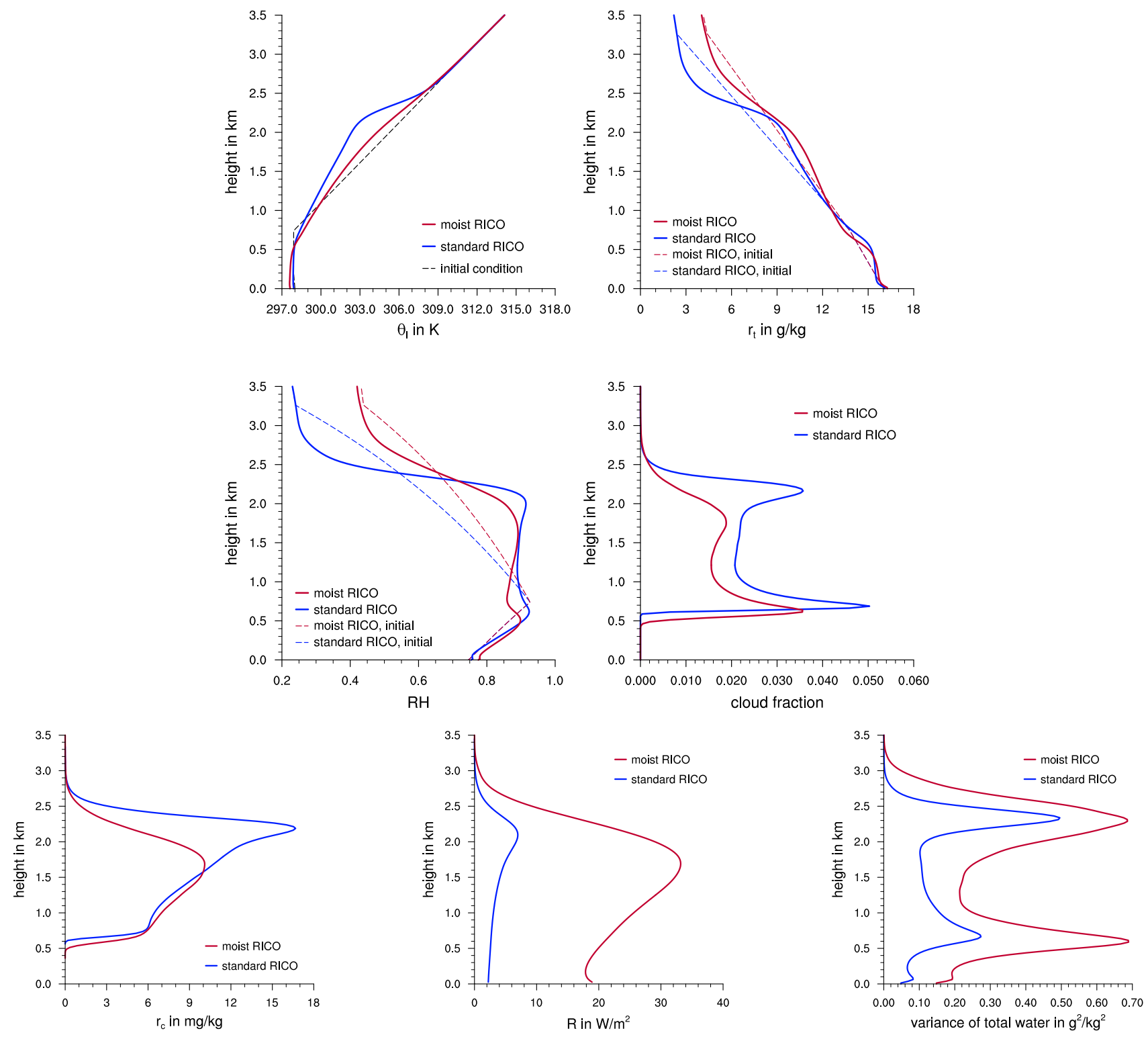

Fig. 3. Mean profiles of the standard GCSS RICO case (blue) and the moist RICO case (red) with the corresponding initial conditions (dashed) on the $25 \mathrm{~km} \times 25 \mathrm{~km}$ domain. Profiles are averages over the entire domain from $24 \mathrm{~h}$ to $30 \mathrm{~h}$ of the simulation. Shown in upper panels from left to right are liquid water potential temperature and total water mixing ratio, and in the 2nd row relative humidity and cloud fraction. On lower panels from left to right are cloud liquid water mixing ratio, rain water flux and the variance of the total water mixing ratio. The rain water flux profile is conditionally averaged over the raining areas.

$\int_{k_{r}}^{k_{\Delta}} S_{r_{\mathrm{t}}}(k) \mathrm{d} k=\frac{2}{3} \int_{0}^{k_{\Delta}} S_{r_{\mathrm{t}}}(k) \mathrm{d} k=\frac{2}{3}\left\langle r_{\mathrm{t}}^{\prime 2}\right\rangle$

in other words, $2 / 3$ of the variance resides at scales smaller than $\Lambda_{r}$ (here $k_{\Delta}$ is the Nyquist wave number). Figure $5 \mathrm{~b}$ shows the time series of the spectral length scale and reveals that the moist case does indeed show a transition to larger scale structures after about $15 \mathrm{~h}$, with the transition being completed after $20 \mathrm{~h}$. This matches well with the vi- sual impression from the corresponding Hovmöller diagrams (Fig. 4b). The standard RICO case shows no significant growth of scale in this diagnostic.

\subsection{Cluster analysis}

With Hovmöller diagrams or the Fourier analysis it is possible to quantify the clustering of clouds and the growth of larger structures, but those methods are still inappropriate to quantify the mode of organization of cumulus cloud 
a) standard RICO case, $25^{2} \mathrm{~km}^{2}$



b) moist RICO case, $25^{2} \mathrm{~km}^{2}$

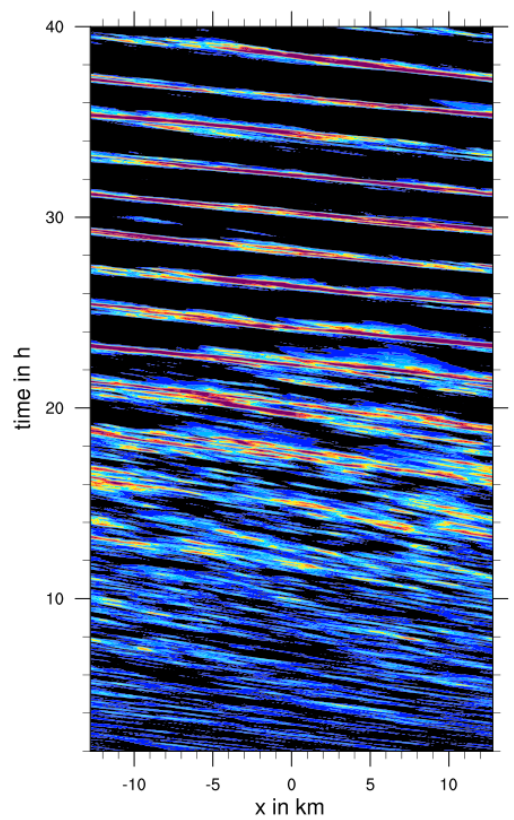

c) moist RICO case, $50^{2} \mathrm{~km}^{2}$

Fig. 4. Hovmöller diagrams of $y$-averaged cloud liquid water path for three different simulations of the RICO trade wind cumulus case. The standard GCSS RICO case on (a) a $25 \mathrm{~km} \times 25 \mathrm{~km}$ domain and (b) the moist case on the same domain and (c) the moist case on a $50 \mathrm{~km} \times 50 \mathrm{~km}$ domain.

a) Variance spectra of total water

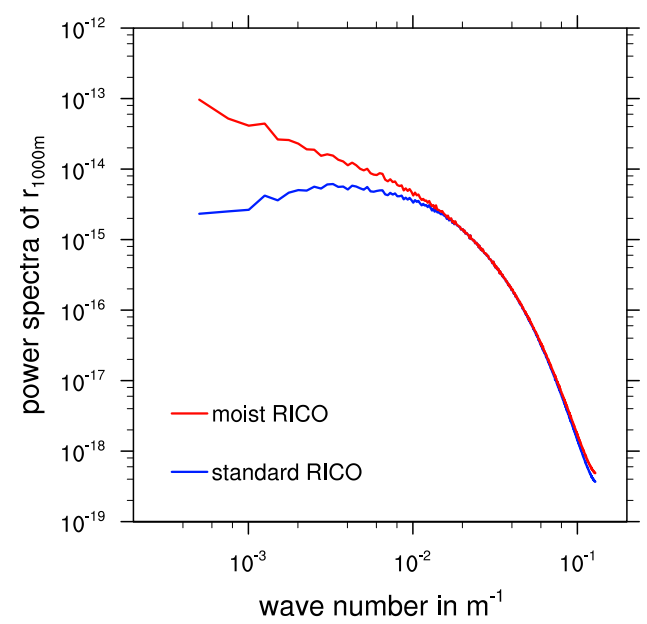

b) Spectral length scale of total water

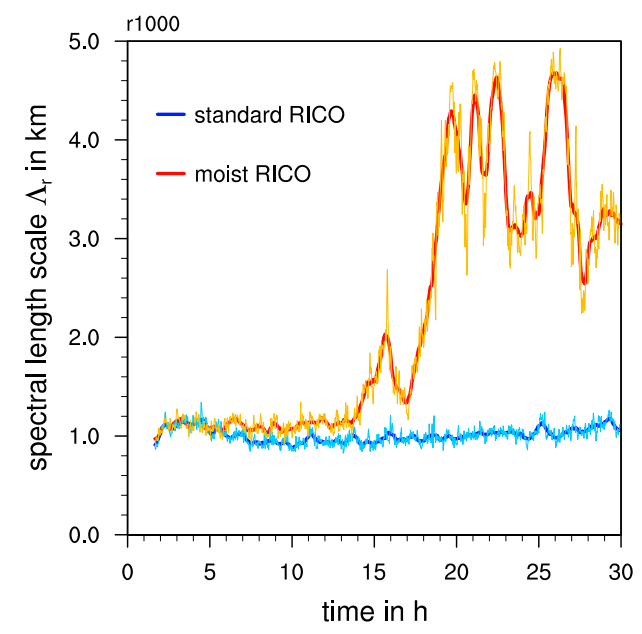

Fig. 5. Power spectra (left) and time series of the spectral length scale $\Lambda_{r}$ (right) of the total water mixing ratio at $1000 \mathrm{~m}$ height for the standard and moist RICO case on the $25 \mathrm{~km} \times 25 \mathrm{~km}$ domain (in the time series plot the red and dark blue lines represent 30 min running averages, orange and light blue lines show the corresponding 1 min data).

fields, i.e. whether the cloud fields show some regular, random or clustered structure. A method to discriminate among these modes of organization is based on the nearest neighbor cumulative distribution function (NNCDF) as described by Weger et al. (1992) and applied, e.g. by Nair et al. (1998).
For this method one has to identify the clouds as individual objects and calculate their positions. To quantify the regularity, randomness or clustering one can then calculate the nearest neighbor distance for each cloud and compare the nearest neighbor distribution function with analytic (or numerical) 
a) integral positive NNCDF deviation

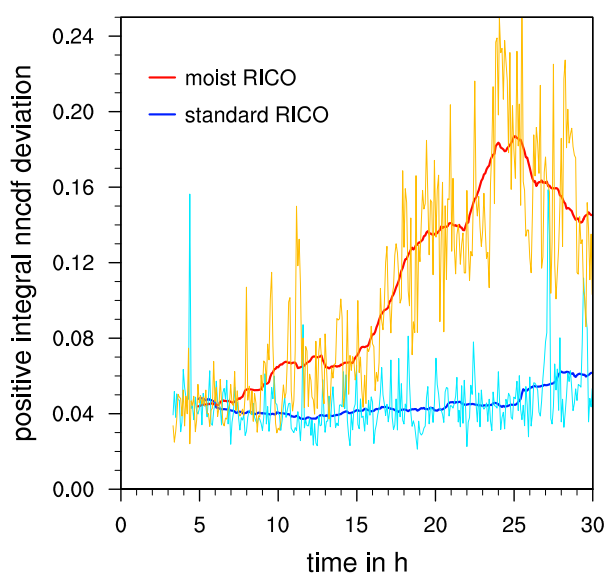

b) cloud number density

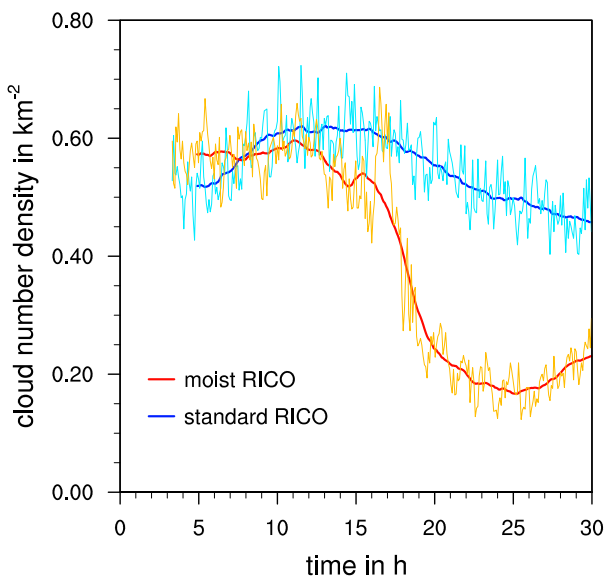

Fig. 6. Time series of the positive integral deviation of the nearest neighbor cumulative distribution (left, higher values indicate stronger clustering) and cloud number density (right) (in the time series plot the red and dark blue lines represent 120 min running averages, orange and light blue lines show the corresponding 1 min data).

solutions for perfectly regular or random fields. Here we use a metric similar to Weger et al. (1992), i.e. we calculate the integral distance or deviation to the nearest neighbor cumulative distribution function of a random field. A positive deviation corresponds to clustering and a negative deviation would indicate a regular cloud field (as one would find if the cloud formed on a regular grid). For the identification and tracking we use an algorithm based on CWP and cloud cores (Heus and Seifert, 2013, in preparation). The details of the tracking algorithm are not important for the results of the cluster analysis presented here. All cloud fields of our RICO simulations show either random or clustered organization, i.e. we did not find any evidence for regular cloud fields. The standard RICO case is very close to random, i.e. small positive NNCDF deviation, with a tendency towards clustering as the simulation progresses (Fig. 6a). As expected the moist RICO simulation shows a much stronger clustering, but the transition is less sharp in the integral NNCDF metric than, e.g. in the corresponding time series of the spectral length scale. After $t=25 \mathrm{~h}$ the clustering does not increase further, which is consistent with the previous diagnostics and the fact that the cloud field does not collapse into a single convective core but retains a spatially extended line of shallow convection cells.

The cloud identification and tracking provides another useful diagnostic in terms of the number of individual clouds in the domain, i.e. the cloud number density (Fig. 6b). For the standard case, the number of clouds increases in the first $10 \mathrm{~h}$ of the simulation followed by a slow quasi-linear decay. In contrast, the moist case shows a rapid depletion of clouds at $t=15 \mathrm{~h}$, i.e. during the transition to the strongly organized cloud field.

\section{Analysis of cloud organization}

\subsection{Perturbed physics LES experiments}

Using diagnostics alone it is difficult to disentangle which physical process leads to the formation of organized cloud structures. Therefore perturbed physics simulation experiments can be helpful to isolate which feedback triggers the transition from a random to an organized cloud field. Bretherton et al. (2005) as well as Muller and Held (2012) have used perturbed physics experiments to investigate selfaggregation in radiative-convective equilibrium simulations of deep convection. They found that the surface flux feedback and radiative feedbacks, especially longwave radiative cooling from low clouds, are responsible for aggregation of clouds in radiative-convective equilibrium simulations. The RICO simulations do not include interactive radiation, but only a prescribed cooling rate. As we assume a fixed SST, the surface flux feedback could contribute to the formation of mesoscale structures. Table 1 summarizes the perturbed physics experiments which we have performed and provides some basics statistics (similar to Tables 2 and 3 of SS08). In addition, Table 1 includes an assessment of the mode of organization, i.e. whether the cloud field remains random (no organization) or shows a clear transition to clustering. These yes/no results are based on an overall evaluation using the techniques presented in the previous section. All perturbed physics experiments have been performed on a $1024 \times 1024$ grid, i.e. a $25 \mathrm{~km} \times 25 \mathrm{~km}$ domain, with an isotropic grid spacing of $25 \mathrm{~m}$ and were run for $30 \mathrm{~h}$ simulation time.

The first perturbed physics experiment, M02, tests whether a homogenization of the surface fluxes can suppress the organization. We find that the surface flux feedback has only 
Table 1. Perturbed physics simulations to investigate the self-organization feedback. Variables are liquid water path LWP, cloud liquid water path CWP, rain water path RWP, fraction of cloudy columns $C$ and surface rain rate $R_{\text {sfc }}$. The last column indicates whether significant organization in clusters occured in the simulations. All variables are averaged over $24-30 \mathrm{~h}$ of each simulation.

\begin{tabular}{llcccccc}
\hline Run & Description & LWP $\left[\mathrm{g} \mathrm{m}^{-2}\right]$ & $\mathrm{CWP}\left[\mathrm{g} \mathrm{m}^{-2}\right]$ & $\mathrm{RWP}\left[\mathrm{g} \mathrm{m}^{-2}\right]$ & $C[-]$ & $R_{\mathrm{sfc}}\left[\mathrm{Wm}^{-2}\right]$ & $\mathrm{Org}$ \\
\hline R01 & standard RICO & 20.3 & 17.7 & 2.6 & 0.19 & 3.0 & no \\
M01 & moist RICO, control & 23.8 & 11.4 & 12.4 & 0.10 & 23.8 & yes \\
M01 big & moist RICO, 50 km domain & 19.6 & 10.4 & 9.2 & 0.14 & 26.0 & yes \\
M02 & homogenized sfc. fluxes & 28.4 & 12.6 & 15.8 & 0.12 & 37.5 & yes \\
M03 & no rain & 25.1 & 25.1 & - & 0.29 & - & no \\
M04 & no evaporation of rain & 27.6 & 17.9 & 9.7 & 0.24 & 21.8 & no \\
M05 & no evap., $z<500 \mathrm{~m}$ & 29.8 & 22.5 & 7.3 & 0.27 & 12.5 & no \\
M06 & no evap., $z<400 \mathrm{~m}$ & 33.0 & 22.8 & 10.2 & 0.26 & 18.0 & no \\
M07 & no evap., $z>450 \mathrm{~m}$ & 17.3 & 6.8 & 10.4 & 0.08 & 23.7 & yes \\
M08 & no evaporative cooling & 16.1 & 6.8 & 9.3 & 0.13 & 31.6 & yes \\
M09 & no evap. cool., $z<450 \mathrm{~m}$ & 33.1 & 24.7 & 8.4 & 0.30 & 13.1 & no \\
M10 & no evap. moist., $z<450 \mathrm{~m}$ & 28.5 & 14.1 & 14.4 & 0.12 & 25.6 & yes \\
\hline
\end{tabular}

a minor impact on the simulation (increase in RWP and rain rate) and no clear effect on the organization. This is to some extent surprising, as the surface fluxes are very important for the properties of the trade wind cumulus cloud layer. A potentially important feedback is the pre-conditioning or moistening of the cloud layer by the shallow convective clouds, i.e. the clouds make the environment more favorable for subsequent development of new clouds. For this feedback we can only test indirectly by asking whether the moist RICO case also organizes when precipitation is inhibited, if preconditioning would be the decisive feedback then rain should not be necessary for the mesoscale organization. Simulation M03 without rain formation shows a much higher CWP and a higher cloud cover than M01 or R01, but the cloud field remains randomly organized and the cloud structures are very similar to the standard control simulation R01. This suggests that rain is a crucial ingredient for the organization of trade wind cumulus clouds.

By turning off evaporation of rain simulation, M04 tests whether cloud organization is associated with rain because of evaporation. Indeed, M04 shows no sign of organization. Three further simulations have been carried out to investigate this in more detail, i.e. whether the cooling/moistening of the sub-cloud layer or a pre-conditioning (moistening) of the cloud layer or the cloud base region is controlling the clustering, hence, evaporation of rain is turned off in some part of the column. These simulations confirm that the evaporation of rain in the sub-cloud layer is most important. The last question which remains is whether the cooling or the moistening of the sub-cloud layer is triggering the organization. Both would be possible, because a moistening of the sub-cloud layer lowers the lifting condensation level (LCL) and can therefore provide a feedback for the formation of new clouds in the wake of precipitating cumuli. In simulation M08 we have turned off the evaporative cooling by rain in the whole column, i.e. keeping only the moistening due to rain. This simulation does indeed show some evidence for clustering, but the other properties of the cloud layer, e.g. CWP and cloud cover, are very different from the control simulation M01. If we turn off the evaporative cooling only in the subcloud layer below $z<450 \mathrm{~m}$, the clouds do not organize into clusters. In contrast, the simulation M10 with the evaporative moistening of the sub-cloud layer turned off, does organize and also all other properties of the cloud field of M10 are similar to the moist control run M01. This suggests that the clustering in simulation M08 is an artifact of the perturbed energetics of this specific simulation which then seems to be able to organize through the precipitation-moistening feedback. Therefore we conclude that, in the regimes characterized by large-scale conditions similar to the forcing assumed for the RICO simulations, the formation of cold pools by evaporation of rain in the sub-cloud layer is indeed the dominant feedback for the organization of precipitating trade wind cumulus.

\subsection{Anatomy of trade wind cumulus cold pools}

In our simulations the cold pools are usually shallow, i.e. the temperature perturbation does not extend through the whole sub-cloud layer. Nevertheless, a vertical average over the sub-cloud layer provides a useful diagnostic to discuss the structure and evolution of the simulated cold pools. Figure 7 shows the deviation of vertically averaged sub-cloud layer temperature and moisture from the horizontal mean. In addition, the clouds are indicated by contours of CWP. Larger cold pools have a pronounced dry core of low $\theta_{e}$ air and a ring of moist air at the cold pool boundary. Weaker cold pools originating from smaller cells often do not have a significant dry core and are, in the later stage of their evolution, best characterized as arcs of moist and cold air. Temperature 
anomalies are below $1 \mathrm{~K}$ and horizontal sizes extend to $20 \mathrm{~km}$ for large cold pools. It is, of course, possible that even larger cold pools would form on a bigger simulation domain.

Most cold pools start their life cycle as a moist cold anomaly when the first precipitation of a convective cell develops, subsequently a downdraft brings down low $\theta_{e}$ air and the spreading cold pool forms a ring of cold moist air with a dry core in the center. In the moist RICO case low $\theta_{e}$ air as cold as $334 \mathrm{~K}$ reaches the surface which corresponds to air from about $800 \mathrm{~m}$ height or above. The ring of moist air can be attributed to both the evaporation of rain and the (moisture) convergence due to the rapidly propagating density current.

New convective cells form at the spreading cold pool boundary where the ring of cold moist air lowers the lifting condensation level (LCL). Whether clouds are mostly thermodynamically initiated, i.e. due to the lower LCL and the water vapor contribution to buoyancy, or triggered dynamically by lifting associated with the propagating density current is difficult to disentangle. The clouds at the cold pool boundary grow rapidly and form the visible mesoscale arcs which are oriented perpendicular to the main wind direction. The regeneration of the cold pool by surface fluxes leads to a moistening and warming of their core. Small cumulus clouds start to form in the regenerating cold pool area. With increasing cloud cover those small clouds organize in cloud streets oriented along the main wind direction (cf. Figs. 1 and 7).

The structure and life cycle of the cold pools in our simulations is strikingly similar to the cold pools simulated and analyzed by Tompkins (2001) for radiative-convective equilibrium simulations of deep convection. The qualitative behavior of the formation of cold pools in precipitating trade wind cumulus has also been described earlier by Xue et al. (2008) based on their LES using a much coarser grid and a smaller domain. Their simulations probably just lacked a sufficient domain size to develop the mesoscale organization. Our findings are also consistent with the observational studies of trade wind cumulus cold pools and mesoscale arcs by Zuidema et al. (2012) and Warner et al. (1979).

\subsection{Sub-cloud layer coupling}

A remarkable property of the simulated trade wind cumulus cloud fields is that the clouds correlate very well with the sub-cloud layer moisture, i.e. clouds usually occur over the moister patches of the sub-cloud layer and even prefer colder rather than warmer areas. This is quantified for our simulations in Fig. 8 where we have conditioned the histograms of the sub-cloud layer anomalies of temperature and moisture on the occurrence of clouds. This behavior is consistent with the analysis of observations during GATE by Nicholls and LeMone (1980) who also found that convective elements in the sub-cloud layer are cooler and wetter than the mean. The correlation between water vapor and clouds still holds for the organized cloud fields which are driven by the cold pool dynamics. This can qualitatively be seen from Fig. 7, from the corresponding movies which are provided as online supplement, and is also confirmed more quantitatively by the statistics provided in Fig. 8. Compared to the randomly organized standard case (Fig. 8a), the clouds in the moist case do prefer the warmer patches (Fig. 8c), because the cold anomalies are occupied by the cold pool areas, which are often drier than the mean (note also the different scales in Fig. 8a, c). The clouds with high cloud base, i.e. the convective outflow, are most often advected over the cold pool, e.g. in the wake of mesoscale arcs. Nevertheless, the fact that the clouds form primarily over the moist patches, even in the organized cloud fields, further supports the interpretation that a main mechanism in the cold pool dynamics is that they lead to the formation of moist patches or rings in the sub-cloud layer. This does not rule out the fact that dynamical processes also play an important role in the triggering, especially of the deeper clouds as, e.g. shown by Böing et al. (2012).

The statistics presented in Fig. 8 aims at revealing the influence of the sub-cloud layer on the formation of the clouds. In contrast to that, Fig. 9 shows the impact of the precipitation on the variability of temperature and moisture in the sub-cloud layer. For this analysis the rain rate is averaged over $15 \mathrm{~min}$ and the data is coarse-grained to a $1 \mathrm{~km}$ spatial resolution to better show the response of the sub-cloud layer to significant rain events. Of course, we find that precipitation does cool the sub-cloud layer due to evaporation of rain. This can be seen in Fig. 9a for the standard case and in Fig. 9c for the moist case. Note that in the moist case the magnitude of the temperature anomalies is much larger, and this is mostly caused by the more intense rainfall. The total PDF of the temperature anomalies (black lines in Fig. 9a, c) is almost Gaussian for the standard case, but negatively skewed for the moist case due to the formation of cold pools. For the standard case the rainfall leads to a weak moistening of the sub-cloud layer (Fig. 9b), while the rain events in the moist case lead to a moistening of some parts of the sub-cloud layer and to a drying in other regions (as described in the previous section), thus increasing the variance of the moisture field. This coupling between precipitation and the variance of water vapor in the sub-cloud layer could be included in prognostic PDF-based cloud cover schemes, e.g. the Tompkins (2002) parameterization. Including this feedback in parameterizations might actually be key for the representation of cold pool-dominated shallow and deep convection.

\section{Sensitivity of cloud organization}

\subsection{Grid spacing}

Although most properties of non-precipitating cumulus clouds are rather robust to the specific choices of the largeeddy simulation (e.g. Siebesma et al., 2003) this is not the 
a) sub-cloud temperature deviation


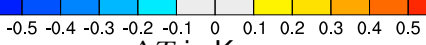

b) sub-cloud moisture deviation
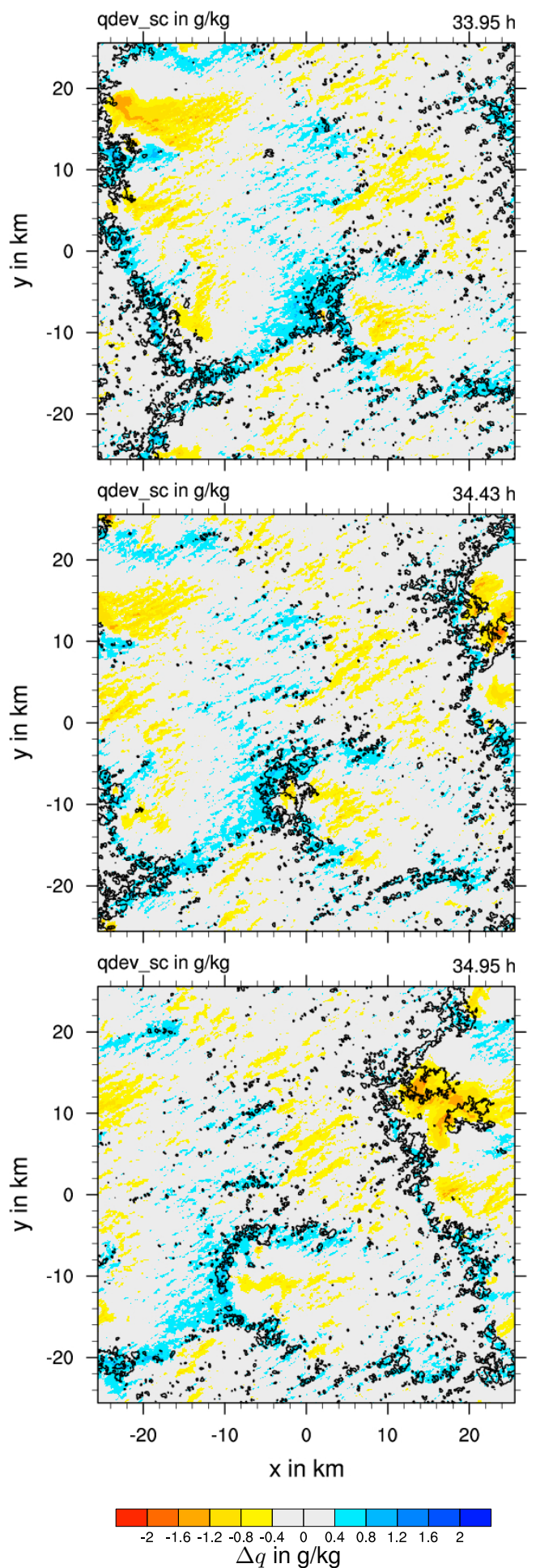

Fig. 7. Temperature (left) and moisture (right) deviation in the sub-cloud layer at different simulation times corresponding to Fig. 1. Isolines show the liquid water path with contour lines at $0.01 \mathrm{~g} \mathrm{~m}^{-2}$ and $1.0 \mathrm{~g} \mathrm{~m}^{-2}$ (black). 
a) temperature deviations (standard case)

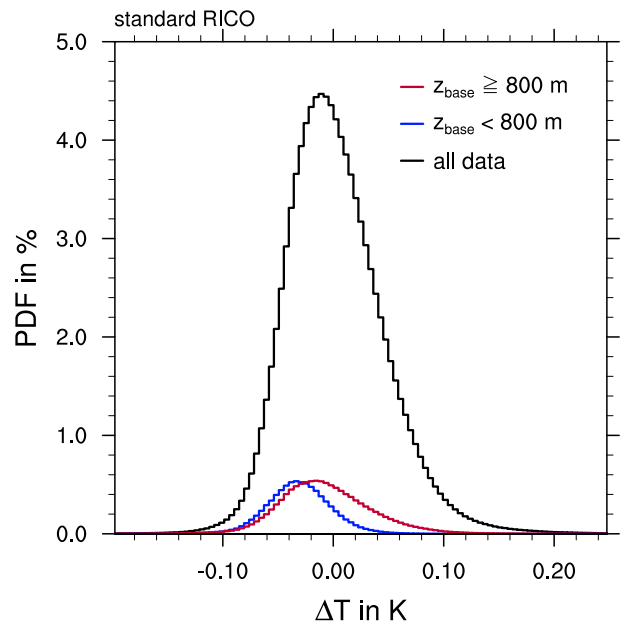

c) temperature deviations (moist case)

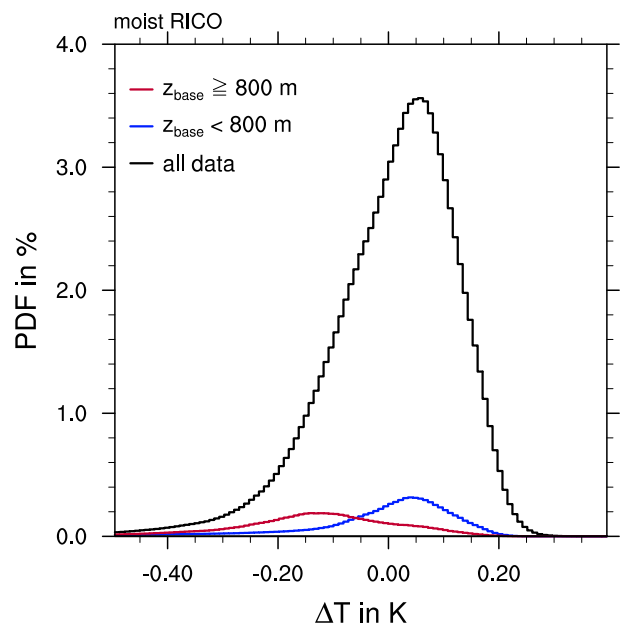

b) moisture deviation (standard case)

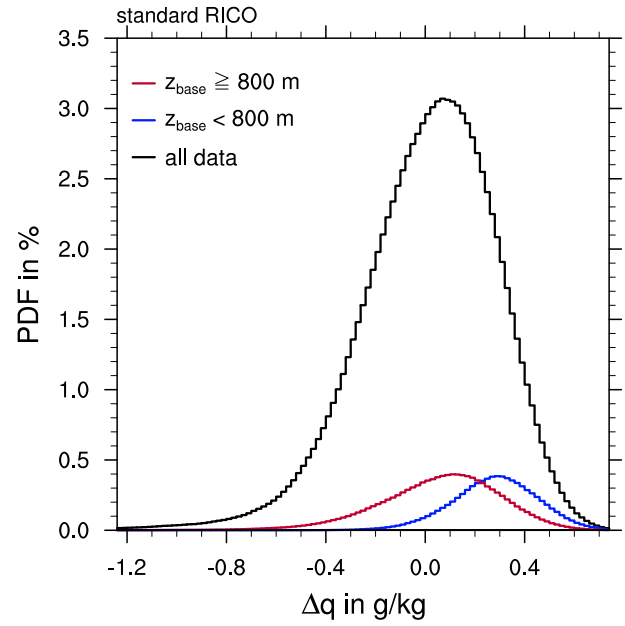

d) moisture deviation (moist case)

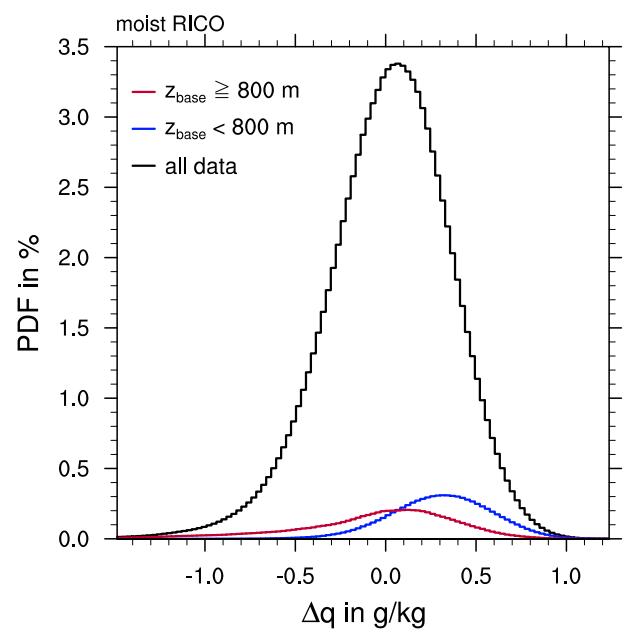

Fig. 8. Histograms of the sub-cloud temperature and moisture anomalies, for all data and sub-sampled for cloudy columns with cloud base below and above $800 \mathrm{~m}$, i.e., the colored lines indicate that part of the PDF which is cloudy with a certain cloud base. Simulation R01 and M01-big sampled over $20 \mathrm{~h}$ to $40 \mathrm{~h}$.

Table 2. Sensitivity simulation to investigate the dependency on grid spacing and cloud droplet number density. Variables are liquid water path LWP, cloud liquid water path CWP, rain water path RWP, fraction of cloudy columns $C$ and surface rain rate $R_{\text {sfc }}$. All variables are averaged over $24-30 \mathrm{~h}$ of each simulation.

\begin{tabular}{llcccccc}
\hline Run & Description & LWP $\left[\mathrm{g} \mathrm{m}^{-2}\right]$ & $\mathrm{CWP}\left[\mathrm{g} \mathrm{m}^{-2}\right]$ & $\mathrm{RWP}\left[\mathrm{g} \mathrm{m}^{-2}\right]$ & $C[-]$ & $R_{\mathrm{sfc}}\left[\mathrm{W} \mathrm{m}^{-2}\right]$ & Org. \\
\hline M01 & moist RICO, control & 23.8 & 11.4 & 12.4 & 0.10 & 23.8 & yes \\
M12 & $\Delta x=50 \mathrm{~m}$ & 42.0 & 18.0 & 24.0 & 0.18 & 49.3 & delayed \\
M13 & $\Delta x=100 \mathrm{~m}$ & 33.7 & 16.0 & 17.7 & 0.13 & 26.3 & delayed \\
M14 & $N_{\mathrm{c}}=85 \mathrm{~cm}^{-3}$ & 47.3 & 25.1 & 22.2 & 0.25 & 44.9 & delayed \\
M15 & $N_{\mathrm{c}}=105 \mathrm{~cm}^{-3}$ & 35.5 & 25.4 & 10.1 & 0.29 & 18.8 & delayed \\
M16 & $N_{\mathrm{c}}=140 \mathrm{~cm}^{-3}$ & 28.7 & 25.5 & 3.2 & 0.29 & 5.8 & no \\
\hline
\end{tabular}


a) temperature deviations (standard case)



c) temperature deviations (moist case)

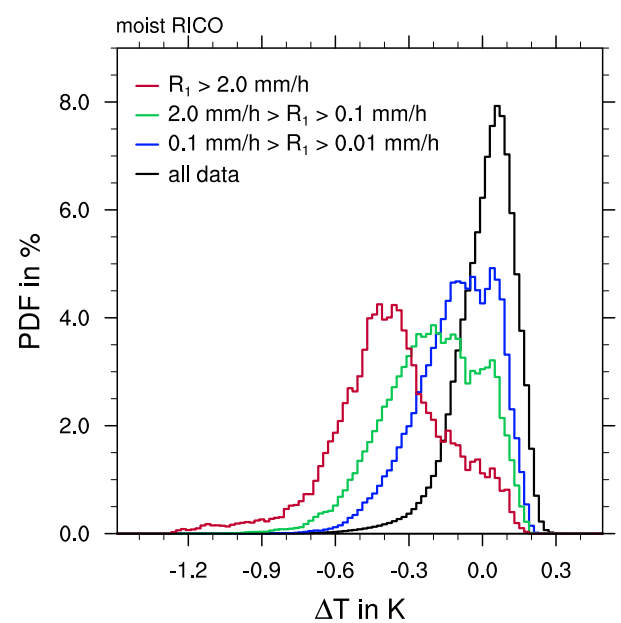

b) moisture deviation (standard case)

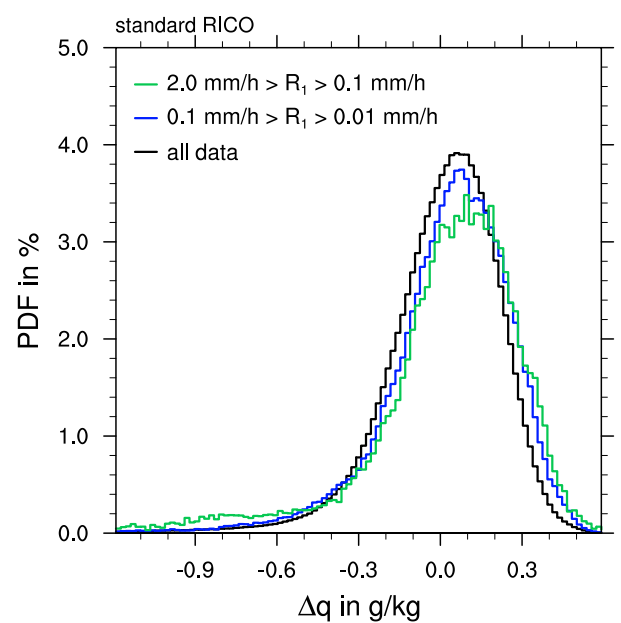

d) moisture deviation (moist case)

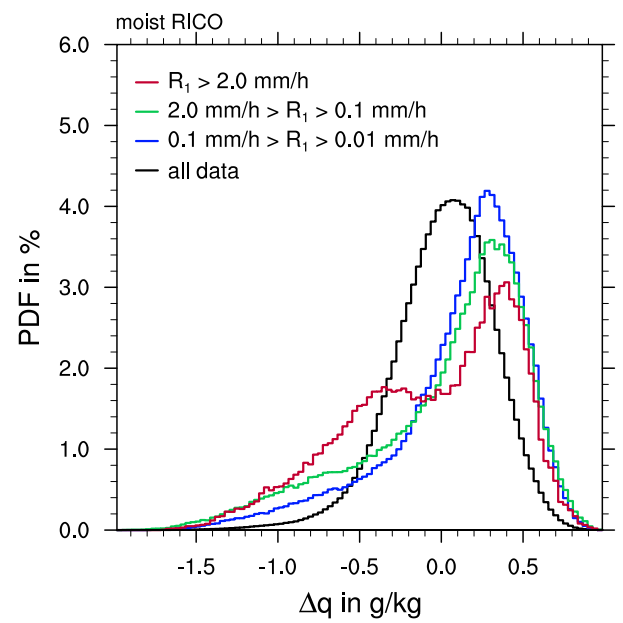

Fig. 9. Histograms of the sub-cloud temperature and moisture anomalies, for all data and conditioned on precipitation rate. The precipitation rate $R_{1}$ is averaged over $15 \mathrm{~min}$ in time, and precipitation rate and anomalies are averaged spatially over $1 \mathrm{~km} \times 1 \mathrm{~km}$. Simulations R01 and M01-big sampled over $20 \mathrm{~h}$ to $40 \mathrm{~h}$. Note that in contrast to Fig. 8 all conditional PDFs are normalized to 1.

case for precipitating trade wind cumulus. The local rain rates and also the domain-averaged precipitation amounts can be quite sensitive to grid spacing, numerical methods and sub-grid closure assumptions (Matheou et al., 2011; Seifert et al., 2012). It is therefore to be expected that the grid spacing also affects the organization of the cloud field. We have performed simulations with larger horizontal grid spacing of $50 \mathrm{~m}$ and $100 \mathrm{~m}$, but keeping the vertical grid spacing at $25 \mathrm{~m}$. The averaged LWP, CWP, RWP and precipitation rate as shown in Table 2 reveal a large impact of the grid spacing on the simulations. The NNCDF cluster analysis shows that a coarser horizontal mesh leads to more random cloud fields and a significant delay in the transition to the cold pooldominated organized regime (Fig. 10a). This shows that high horizontal resolution is crucial for the large-eddy simulation of organized precipitating shallow convection.

\subsection{Cloud droplet number}

The rain formation in warm boundary layer clouds can exhibit a significant sensitivity to the number density of cloud condensation nuclei $(\mathrm{CCN})$ or cloud droplets (e.g. SavicJovcic and Stevens, 2008; Xue et al., 2008; Stevens and Seifert, 2008). For a stratocumulus cloud layer the precipitation can lead to a transition from closed to open cells, i.e. by their impact on the mode of organization aerosols may have a significant effect on the macroscopic properties of a stratocumulus layer (Savic-Jovcic and Stevens, 2008; Wang and Feingold, 2009; Berner et al., 2011). Does the organization of trade wind cumulus cloud field by cold pool 
a) grid spacing

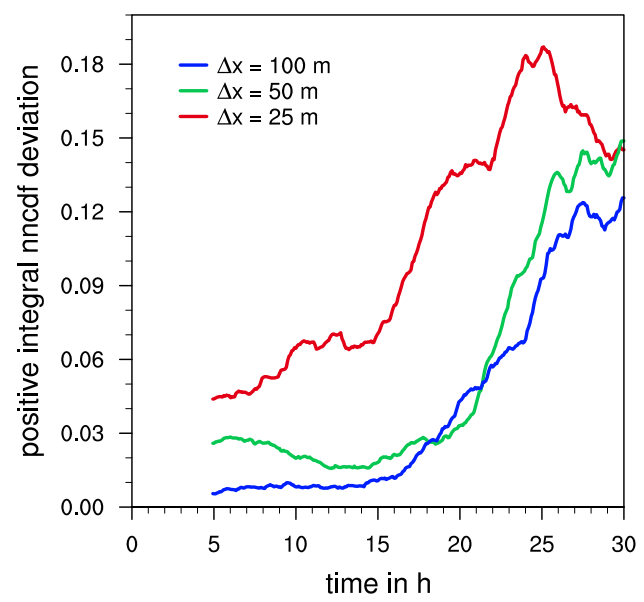

b) cloud droplet number

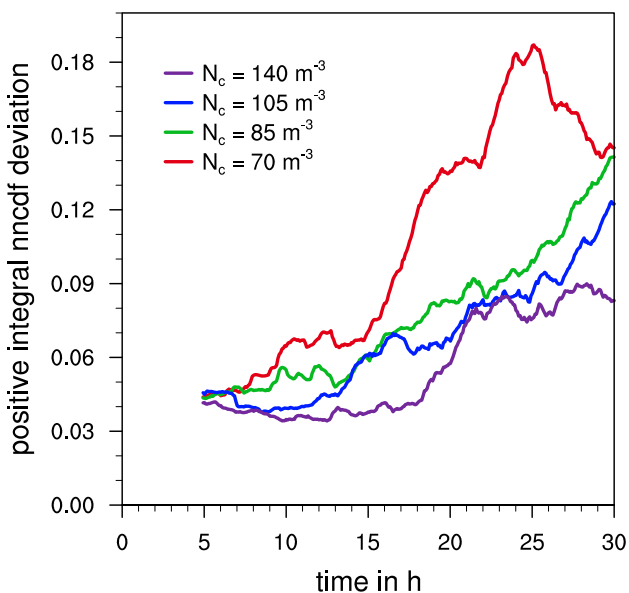

Fig. 10. Time series of the positive integral deviation of the nearest neighbor cumulative distribution (higher values indicate stronger clustering). Shown are the simulations M01, M12 and M13 (left) and M01 together with M14-M16 (right).

dynamics lead to a similar sensitivity to aerosol assumptions? This is investigated by simulations M14-M16, which assume higher cloud droplet number concentrations than the moist control run M01, which assumes $N_{\mathrm{c}}=70 \mathrm{~cm}^{-3}$. The simulations with higher cloud droplet number have roughly twice the CWP and cloud cover of the control run M01. Rain water path and rain rate vary strongly with cloud droplet number, e.g. M14 with $N_{\mathrm{c}}=85 \mathrm{~cm}^{-3}$ has a much higher RWP and almost twice the rain rate as the control M01; for simulations M15 and M16 with higher $N_{\mathrm{c}}$ both, RWP and rain rate decrease, i.e. for the moist RICO case the RWP and rain rate show a non-monotonic dependency on $N_{\mathrm{c}}$. This nonmonotonic behavior can be explained by the fact that a higher cloud droplet number concentration delays and weakens the cloud organization through the cold pools dynamics, simply because it rains less. The increase in rain rate in simulation M14 compared to M01 is probably due to the transient behavior of the simulations, i.e. in the period of 24-30 h which is used for the statistics the simulation M14 is going through the transition to organization and this includes the formation of a large heavily raining cloud cluster (comparable to 15$20 \mathrm{~h}$ of M01). This delay in organization can be quantified using the NNCDF cluster analysis (Fig. 10b) which confirms the strong impact of the cloud microphysical assumptions on the evolution of the cloud field. The simulation M16 shows a weak tendency towards clustering, but the NNCDF metric as well as RWP and rain rate are much more similar to the standard RICO simulation R01 than to the other moist cases. This suggests that the clustering is, by the formation of cold pools, indeed mostly controlled by the local rain rate and this makes the onset of organization susceptible to perturbations in the microphysical assumptions, e.g. $\mathrm{CCN}$ or cloud droplet concentrations.

\section{Conclusions}

We have presented large-eddy simulations of organized precipitating shallow convection which reproduce many typical features observed for precipitating trade wind cumulus cloud fields, e.g, the along-wind cloud streets consisting of smaller non-precipitating clouds and the across-wind mesoscale arcs of precipitating shallow convection and their corresponding cold pools. This demonstrates that, given high enough resolution and a large enough domain size, fairly standard LES models are in fact able to simulate this important cloud regime, i.e. the lack of such simulations in the literature pointed out by Zuidema et al. (2012) is mostly due to computational constraints. In fact, Xue et al. (2008) describe many features of organized precipitating shallow convection based on their simulations which probably just lacked the sufficient domain size for mesoscale organization.

Perturbed physics experiments support the hypothesis that the formation of cold pools by evaporation of rain in the subcloud layer is the dominant feedback which leads to the formation of cloud clusters and mesoscale arcs. Consistent with the analysis of Tompkins (2001) for tropical deep convection, we find that the formation of moist patches in the sub-cloud layer, e.g. as moist rings surrounding the cold pool boundaries, plays an important role in the clustering process.

Our simulations show clearly that the observed cloud structures, including the mesoscale arcs, can be explained by the self-organization of precipitating trade wind cumulus clouds. This suggests that such highly organized structures can emerge even in cases when the surface conditions (SST) and large-scale forcing are perfectly homogeneous. It does of course not rule out that heterogeneities in SST or in the largescale forcing may play a role in modulating the cloud fields 
in nature. It is in contrast most likely that the observed cloud fields emerge from a combination of all these ingredients.

The capability to do such large-domain large-eddy simulations as we have presented is just emerging and even our simulations would still benefit from higher resolution and larger domain size. The latter would be important to quantify the recovery time of the cold pools and the question whether this process introduces its own length scale, i.e, whether there is a typical length scale for the distance between two mesoscale arcs which is inherent in the dynamics and microphysics of the problem, or whether this distance is mostly determined by the large scale forcing. There are many other aspects of the mesoscale structure that merit further study, such as the role of gravity waves and mesoscale circulations. The resolution issue inherent in our simulations is mostly related to the microphysics of rain formation and the lack of convergence at $25 \mathrm{~m}$ grid spacing suggests that the internal variability of the clouds at scales of a few tens of meters could be important for the efficiency of the warm rain process, either by variability or due to recirculation of droplets.

It is important to recognize that the organized trade wind cumulus regime is different from open cell stratocumulus, e.g. the cold pools in trade wind cumulus do often have a pronounced dry core, i.e. low $\theta_{e}$, while the cloud free areas in open cell stratocumulus are moist and have high $\theta_{e}$ (SavicJovcic and Stevens, 2008; Zuidema et al., 2012). In this sense organized precipitating trade wind cumulus convection behaves more similar to tropical deep convection and much of our analysis bears many similarities to previous work on radiative-convective equilibrium of deep convection, e.g. by Tompkins (2001).

The ability to simulate this cloud regime opens up new opportunities to answer many questions related to organized trade wind cumulus clouds and the associated cold pools, e.g.

- What is the relation between the cloud size, cloud depth and life cycle of a convective cell and the formation and properties of the cold pool it generates?

- What is the role of low level wind shear in the organization of shallow convection? Can RKW theory (Rotunno et al., 1988) be applied to explain the formation, propagation and structure of mesoscale arcs in shallow convection?

- Why does shallow convection not self-aggregate into a single cluster like deep convection in radiative convective equilibrium?

- Can aerosol properties significantly affect the cloud cover in the trades by changing the mode of organization of trade wind cumulus cloud fields?

We hope that our simulations can provide the basis for investigations to clarify these questions in the future.

\author{
Supplementary material related to this article is \\ available online at: http://www.atmos-chem-phys.net/13/ \\ 5631/2013/acp-13-5631-2013-supplement.zip.
}

Acknowledgements. We thank Louise Nuijens and Bjorn Stevens for critical, encouraging and at times openly skeptical comments and discussions which helped us to reject some of our initial hypotheses. We are also thankful for their and Cathy Hohenegger's comments on the first version of the manuscript. The comments of the two anonymous reviewers are also acknowledged. We acknowledge many helpful comments and questions from participants of the workshop "Towards global LES" at Castle Ringberg in June 2012. This research was carried out as part of the Hans Ertel Centre for Weather Research. This research network of Universities, Research Institutes and the Deutscher Wetterdienst is funded by the BMVBS (Federal Ministry of Transport, Building and Urban Development). We thank ECMWF and DWD for providing the supercomputing resources for this research.

Edited by: C. Hoose

\section{References}

Atkinson, B. and Zhang, J.: Mesoscale shallow convection in the atmosphere, Rev. Geophys., 34, 403-431, 1996.

Berner, A. H., Bretherton, C. S., and Wood, R.: Large-eddy simulation of mesoscale dynamics and entrainment around a pocket of open cells observed in VOCALS-REx RF06, Atmos. Chem. Phys., 11, 10525-10540, doi:10.5194/acp-11-10525-2011, 2011.

Böing, S. J., Jonker, H. J. J., Siebesma, A. P., and Grabowski, W. W.: Influence of the Subcloud Layer on the Development of a Deep Convective Ensemble, J. Atmos. Sci., 69, 2682-2698, 2012.

Bretherton, C., Blossey, P., and Khairoutdinov, M.: An energybalance analysis of deep convective self-aggregation above uniform SST, J. Atmos. Sci., 62, 4273-4292, 2005.

Carbone, R., Tuttle, J., Ahijevych, D., and Trier, S.: Inferences of predictability associated with warm season precipitation episodes, J. Atmos. Sci., 59, 2033-2056, 2002.

Cotton, W. R., Bryan, G. H., and van den Heever, S. C.: Storm and cloud dynamics, vol. 99 of International Geophysics Series, Academic Press, 2nd edition edn., 2011.

de Roode, S., Duynkerke, P., and Jonker, H.: Large-eddy simulation: How large is large enough?, J. Atmos. Sci., 61, 403-421, 2004.

Etling, D. and Brown, R.: Roll vortices in the planetary boundary layer: A review, Bound.-Lay. Meteorol., 65, 215-248, doi:10.1007/BF00705527, 1993.

Jeevanjee, N. and Romps, D. M.: Convective self-aggregation, cold pools, and domain size, Geophys. Res. Lett., 40, 994-998, doi:10.1002/grl.50204, 2013.

Khairoutdinov, M. F. and Randall, D. A.: Similarity of deep continental cumulus convection as revealed by a three-dimensional cloud-resolving model, J. Atmos. Sci., 59, 2550-2566, doi:10.1175/1520-0469(2002)059<2550:SODCCC > 2.0.CO;2, 2002. 
Kuang, Z. and Bretherton, C. S.: A mass-flux scheme view of a high-resolution simulation of a transition from shallow to deep cumulus convection, J. Atmos. Sci., 63, 1895-1909, 2006.

Li, Y. and Carbone, R.: Excitation of Rainfall over the Tropical Western Pacific, J. Atmos. Sci., 69, 2983-2994, 2012.

Malkus, J.: Trade cumulus cloud groups - some observations suggesting a mechanism of their origin, Tellus, 9, 33-44, 1957.

Malkus, J. and Riehl, H.: Cloud structure and distributions over the tropical pacific ocean, Tellus, 16, 275-287, 1964.

Matheou, G., Chung, D., Nuijens, L., Stevens, B., and Teixeira, J.: On the Fidelity of Large-Eddy Simulation of Shallow Precipitating Cumulus Convection, Mon. Weather Rev., 139, 2918-2939, 2011.

Minor, H. A., Rauber, R. M., Göke, S., and Di Girolamo, L.: Trade Wind Cloud Evolution Observed by Polarization Radar: Relationship to Giant Condensation Nuclei Concentrations and Cloud Organization, J. Atmos. Sci., 68, 1075-1096, doi:10.1175/2010JAS3675.1, 2011.

Muller, C. J. and Held, I. M.: Detailed Investigation of the SelfAggregation of Convection in Cloud-Resolving Simulations, J. Atmos. Sci., 69, 2551-2565, 2012.

Müller, G. and Chlond, A.: Three-dimensional numerical study of cell broadening during cold-air outbreaks, Bound.-Lay. Meteorol., 81, 289-323, 1996.

Nair, U., Weger, R., Kuo, K., and Welch, R.: Clustering, randomness, and regularity in cloud fields -5 . The nature of regular cumulus cloud fields, J. Geophys. Res., 103, 11363-11380, doi:10.1029/98JD00088, 1998.

Nicholls, S. and LeMone, M.: The fair weather boundary-layer in GATE: The relationship of sub-cloud fluxes and structure to the distribution and enhancement of cumulus clouds, J. Atmos. Sci., 37, 2051-2067, 1980.

Randall, D. and Huffman, G.: A stochastic-model of cumulus clumping, J. Atmos. Sci., 37, 2068-2078, 1980.

Rauber, R. M., Stevens, B., Ochs, III, H. T., Knight, C., Albrecht, B. A., Blyth, A. M., Fairall, C. W., Jensen, J. B., Lasher-Trapp, S. G., Mayol-Bracero, O. L., Vali, G., Anderson, J. R., Baker, B. A., Bandy, A. R., Burnet, E., Brenguier, J. L., Brewer, W. A., Brown, P. R. A., Chuang, P., Cotton, W. R., Girolamo, L. D., Geerts, B., Gerber, H., Goke, S., Gomes, L., Heikes, B. G., Hudson, J. G., Kollias, P., Lawson, R. P., Krueger, S. K., Lenschow, D. H., Nuijens, L., O'Sullivan, D. W., Rilling, R. A., Rogers, D. C., Siebesma, A. P., Snodgrass, E., Stith, J. L., Thornton, D. C., Tucker, S., Twohy, C. H., and Zuidema, P.: Rain in shallow cumulus over the ocean - The RICO campaign, B. Am. Meteorol. Soc., 88, 1912-1928, doi:10.1175/BAMS-88-12-1912, 2007.

Rotunno, R., Klemp, J. B., and Weisman, M. L.: A theory for strong, long-lived squall lines, J. Atmos. Sci., 45, 463-485, 1988.

Savic-Jovcic, V. and Stevens, B.: The structure and mesoscale organization of precipitating stratocumulus, J. Atmos. Sci., 65, 15871605,2008

Seifert, A.: On the parameterization of evaporation of raindrops as simulated by a one-dimensional rainshaft model, J. Atmos. Sci., 65, 3608-3619, 2008.

Seifert, A. and Beheng, K. D.: A double-moment parameterization for simulating autoconversion, accretion and selfcollection, Atmos. Res., 59-60, 265-281, 2001.

Seifert, A., Sakradzija, M., Heus, T., and Stevens, B.: Resolution and domain size requirements for the large-eddy sim- ulation of precipitating trade wind cumulus, in: Proc. 16th Int. Conf. Clouds and Precip., Leipzig, Germany, 2012.

Siebesma, A., Bretherton, C., Brown, A., Chlond, A., Cuxart, J., Duynkerke, P., Jiang, H., Khairoutdinov, M., Lewellen, D., Moeng, C., Sanchez, E., Stevens, B., and Stevens, D.: A large eddy simulation intercomparison study of shallow cumulus convection, J. Atmos. Sci., 60, 1201-1219, 2003.

Snodgrass, E. R., Di Girolamo, L., and Rauber, R. M.: Precipitation Characteristics of Trade Wind Clouds during RICO Derived from Radar, Satellite, and Aircraft Measurements, J. Appl. Met., 48, 464-483, 2009.

Stevens, B.: Introduction to UCLA-LES, Version 3.2.1, available from: Gitorious at https://gitorious.org/uclales, 2010.

Stevens, B. and Seifert, A.: Understanding macrophysical outcomes of microphysical choices in simluations of shallow cumulus convection, J. Met. Soc. Jap., 86, 143-162, 2008.

Stevens, B., Moeng, C., and Sullivan, P.: Large-eddy simulations-of radiatively driven convection: Sensitivities to the representation of small scales, J. Atmos. Sci., 56, 3963-3984, 1999.

Stevens, B., Moeng, C., Ackerman, A., Bretherton, C., Chlond, A., de Roode, S., Edwards, J., Golaz, J., Jiang, H., Khairoutdinov, M., Kirkpatrick, M., Lewellen, D., Lock, A., Muller, F., Stevens, D., Whelan, E., and Zhu, P.: Evaluation of large-Eddy simulations via observations of nocturnal marine stratocumulus, Mon. Weather Rev., 133, 1443-1462, 2005.

Tompkins, A.: Organization of tropical convection in low vertical wind shears: The role of cold pools, J. Atmos. Sci., 58, 1650 1672, 2001.

Tompkins, A.: A prognostic parameterization for the subgrid-scale variability of water vapor and clouds in large-scale models and its use to diagnose cloud cover, J. Atmos. Sci., 59, 1917-1942, 2002.

van Zanten, M., Stevens, B., Nuijens, L., Siebesma, A., Ackerman, A., Burnet, F., Cheng, A., Couvreux, F., Jiang, H., Khairoutdinov, M., Kogan, Y., Lewellen, D., Mechem, D., Nakamura, K., Noda, A., Shipway, B., Slawinska, J., Wang, S., and Wyszogrodzki, A.: Controls on precipitation and cloudiness in simulations of tradewind cumulus as observed during RICO, J. Adv. Model. Earth Syst., 3, doi:10.1029/2011MS000056, 2011.

Wang, H. and Feingold, G.: Modeling Mesoscale Cellular Structures and Drizzle in Marine Stratocumulus. Part I: Impact of Drizzle on the Formation and Evolution of Open Cells, J. Atmos. Sci., 66, 3237-3256, 2009.

Warner, C., Simpson, J., Martin, D. W., Suchman, D., Mosher, F. R., and Reinking, R. F.: Shallow Convection on Day 261 of GATE: Mesoscale Arcs, Mon. Weather Rev., 107, 101-112, 1979.

Weger, R., Lee, J., Zhu, T., and Welch, R.: Clustering, randomness and regularity in cloud fields: 1 . theoretical considerations, J. Geophys. Res., 97, 20519-20536, 1992.

Xue, H., Feingold, G., and Stevens, B.: Aerosol effects on clouds, precipitation, and the organization of shallow cumulus convection, J. Atmos. Sci., 65, 392-406, 2008.

Zhang, Y., Stevens, B., and Ghil, M.: On the diurnal cycle and susceptibility to aerosol concentration in a stratocumulus-topped mixed layer, Quart. J. Roy. Met. Soc., 131, 1567-1583, 2005.

Zuidema, P., Li, Z., Hill, R. J., Bariteau, L., Rilling, B., Fairall, C., Brewer, W. A., Albrecht, B., and Hare, J.: On Trade Wind Cumulus Cold Pools, J. Atmos. Sci., 69, 258-280, 2012. 